\title{
ANALISIS HUBUNGAN MOTIVASI DAN KEPUASAN KERJA DENGAN KEDISIPLINAN GURU PENDIDIKAN AGAMA ISLAM DI SEKOLAH DASAR
}

\author{
Endin \\ SDN Panyindangan Majalengka, Indonesia \\ endin28@gmail.com
}

\begin{abstract}
Discipline is a characteristic of Muslim teachers because Islamic teachings teach followers to respect the time and respect the rules. This study was conducted with the aim of finding a picture and analyzing the extent of the relationship between motivation and job satisfaction with PAI teacher discipline in the Public Elementary Schools in the Banjaran District, Majalengka Regency. The population in this study were all PAI teachers who were in the Banjaran District Majalengka District Elementary School. The conclusion of this study is from the results of the study, a simple correlation test ( $r$ ) obtained a correlation between the work motivation of PAI teachers and PAI teacher discipline in the strong category. Based on a simple correlation test also obtained a correlation between PAI teacher job satisfaction with PAI teacher discipline with a strong category. Based on the multiple regression test, the correlation between PAI teacher work motivation and PAI teacher job satisfaction together with PAI teacher discipline with the strong category.
\end{abstract}

Keywords: motivation; job satisfaction; discipline; Islamic education.

\begin{abstract}
ABSTRAK
Kedisiplinan merupakan ciri guru muslim, karena ajaran Islam mengajarkan agar pemeluknya menghargai waktu dan menghormati peraturan. Penelitian ini dilakukan dengan tujuan untuk menemukan gambaran dan menganalisis sejauhmana hubungan motivasi dan kepuasan kerja dengan kedisiplinan guru PAI di Sekolah Dasar Negeri Se-Kecamatan Banjaran Kabupaten Majalengka. Populasi dalam penelitian ini adalah seluruh guru PAI yang berada di SD Negeri Kecamatan Banjaran Kabupaten Majalengka. Kesimpulan penelitian ini adalah dari hasil penelitian, uji korelasi sederhana (r) didapat korelasi antara motivasi kerja guru PAI terhadap kedisiplinan guru PAI hubungan dalam kategori kuat. Berdasarkan uji korelasi sederhana pula didapat korelasi antara kepuasan kerja guru PAI terhadap kedisiplinan guru PAI dengan kategori kuat. Adapun berdasarkan uji regresi ganda didapat korelasi antara motivasi kerja guru PAI dan kepuasan kerja guru PAI secara bersama-sama terhadap kedisiplinan guru PAI dengan kategori kuat.
\end{abstract}

Kata Kunci: motivasi; kepuasan kerja; disiplin; pendidikan agama islam.

Submitted Jan 25, 2020 | Revised Feb 11, 2020 | Accepted Feb 21, 2020

\section{Pendahuluan}

Sekolah masa depan yang diharapkan adalah sekolah yang minimal memenuhi Standar Nasional Pendidikan, yang bertujuan menjamin mutu pendidikan nasional dalam rangka mencerdaskan kehidupan bangsa dan membentuk watak serta peradaban bangsa yang bermartabat. Standar Nasional Pendidikan (SNP) berfungsi sebagai dasar dalam perencanaan, pelaksanaan, dan pengawasan pendidikan dalam rangka mewujudkan pendidikan nasional yang bermutu. Standar Nasional Pendidikan (SNP) sebagaimana yang dirumuskan pada Peraturan 
Pemerintah Nomor 19 tahun 2005 pasal I ayat (1) adalah kriteria minimal tentang sistem pendidikan di seluruh wilayah hukum Negara Kesatuan Republik Indonesia.

Keinginan pemerintah untuk melaksanakan reformasi dalam kehidupan berbangsa dan bernegara di bidang pendidikan lebih nampak dengan dikeluarkannya Undang-Undang Nomor 20 tahun 2003 tentang Sistem Pendidikan Nasional (Sisdiknas). Berdasarkan kebutuhan peningkatan mutu pendidikan, dalam hal ini adalah motivasi kerja diperlukan, disamping kepuasan kerja dan disiplin kerja yang memadai, agar mampu melaksanakan berbagai pekerjaan atau tugas yang dibebankan kepadanya. Guru sebagai garda terdepan di bidang pendidikan, harus terus melakukan pengembangan diri secara berkelanjutan agar menjadi guru yang mampu menghasilkan sumber daya manusia yang berkualitas (Nahdi \& Cahyaningsih, 2019). Guru PAI menjadi komponen yang paling berperan dalam meningkatkan motivasi kerja, kepuasan kerja dan disiplin kerja, karena hal tersebut akan menentukan kehidupan sekolah maju dan berkembang, sehingga pelayanan proses pembelajaran Pendidikan Agama Islam maksimal. Guru PAI juga merupakan motor penggerak bagi pendidikan sekolah terutama dalam pembelajaran serta perubahan sikap dan perilaku. Begitu besarnya peranan guru PAI dalam proses pencapaian tujuan pendidikan baik dibidang IPTEK maupun IMTAQ, sehingga dapat dikatakan bahwa sukses tidaknya kegiatan sekolah sebagian besar ditentukan oleh kualitas unsur guru terutama guru PAI.

Segenap sumber daya harus didayagunakan sedemikian rupa. Para guru PAI perlu digerakkan ke arah suasana kerja yang positif, menggairahkan dan produktif. Bagaimanapun guru PAI merupakan input yang hubungannya sangat besar pada proses belajar dan pembentukan watak yang berakhlak mulia. Demikian pula penanaman sikap yang baik, penataan fisik dan administrasi atau ketatalaksanaan perlu dibina agar disiplin dan semangat belajar yang tinggi bagi siswa. Ini semua mensyaratkan perlunya penerapan disiplin kerja bagi guru PAI.

Disiplin merupakan salah satu faktor yang mempengaruhi kinerja pegawai (Irwanto \& Melinda, 2015). Disiplin adalah kesadaran dan keinsafan dengan peraturan-peraturan atau ketentuan-ketentuan yang berlaku dalam organisasi (Hasibuan, 2001). Dengan kata lain, kedisiplinan merupakan ketaatan kepada lembaga atau organisasi dan apa saja yang menjadi ketentuan yang didasarkan kepada keinsafan dan kesadaran dari dalam diri sendiri, dan bukan berdasarkan kepada disiplin yang bersifat mekanis yang dihasilkan dari unsur paksaan.

Disiplin kerja dapat didefinisikan sebagai suatu sikap menghormati, menghargai, patuh dan taat dengan peraturan-peraturan yang berlaku, baik yang tertulis maupun tidak tertulis serta sanggup menjalankannya dan tidak mengelak untuk menerima sanksi-sanksinya apabila ia melanggar tugas dan wewenang yang diberikan kepadanya (Sastrohadiwiryo, 2002). Sedangkan Nawawi (2000) berpendapat bahwa disiplin artinya untuk memelihara stabilitas organisasi dengan memberikan pembatasan mengenai apa yang boleh dilakukan oleh personel dalam suatu organisasi kerja. Disiplin dapat membentuk kesediaan atau kemampuan setiap personil untuk membatasi diri sendiri dengan tidak mengutamakan kepentingan pribadi, akan tetapi sebaliknya selalu didorong untuk mendahulukan kepentingan pekerjaan.

Berdasarkan beberapa pengertian disiplin kerja yang dikemukakan oleh para ahli di atas, dapat disimpulkan bahwa pegawai yang dikatakan memiliki disiplin kerja tinggi adalah pegawai yang taat dan patuh dengan peraturan-peraturan, ketentuan-ketentuan yang berlaku di dalam organisasi baik yang tertulis rnaupun yang tidak tertulis, yang didasari oleh kesadaran, 
keinsafan, dan rasa tanggung jawab dengan tugas dan wewenang yang diberikan kepadanya, serta memiliki kesanggupan untuk melaksanakan dan mengutamakan kepentingan pekerjaan organisasi daripada kepentingan pribadinya.

Salah satu langkah yang dapat dilakukan untuk meningkatkan kedisiplinan adalah kepuasan kerja. Hal ini karena kepuasan kerja dapat menentukan sikap karyawan terhadap pekerjaannya. Kepuasan kerja dapat mempengaruhi disiplin kerja karyawan kearah yang lebih baik, hal ini disebabkan karena karyawan telah mencapai kepuasan psikologis yang memunculkan sikap positif dari karyawan (Ilahi, Mukzam, \& Prasetya, 2017). "Disiplin yang baik mencerminkan besarnya tanggung jawab seseorang terhadap tugas-tugas yang diberikan kepadanya. Hal ini mendorong gairah kerja, semangat kerja, dan terwujudnya tujuan perusahaan, karyawan, serta masyarakat pada umumnya" (Rivai dan Sagala, 2010). Robbins dan Judge (2008:99) berpendapat bahwa "Seseorang dengan tingkat kepuasan kerja yang tinggi memiliki perasaan-perasaan positif tentang pekerjaan tersebut, sementara seseorang yang tidak puas memiliki perasaan-perasaan yang negatif tentang pekerjaan tersebut". Kreitner dan Kinicki (2005:272) berpendapat bahwa "Kepuasan berasal dari persepsi seseorang bahwa output pekerjaan, relatif sama dengan inputnya, perbandingan yang mendukung output atau input lainnya yang signifikan".

Komponen lain yang dapat meningkatkan kedisiplinan kerja guru PAI adalah motivasi kerja guru PAI. Robbins (2006) mendefinisikan motivasi sebagai suatu proses yang ikut menentukan intensitas arah, dan ketekunan individu dalam usaha mencapai sasaran. Menurut Malthis \& Jackson (2001) motivasi adalah merupakan hasrat didalam diri seseorang yang menyebabkan orang tersebut melakukan tindakan. Sedarmayanti (2008) juga mengungkapkan bahwa, "motivasi merupakan kesediaan mengeluarkan tingkat upaya tinggi kearah tujuan organisasi yang dikondisikan oleh kemampuan upaya itu untuk memenuhi kebutuhan individual." Pegawai yang memiliki sikap pejuang, pengabdian, disiplin, dan kemampuan profesional sangat mungkin mempunyai prestasi kerja dalam melaksanakan tugas sehingga lebih berdaya guna dan berhasil guna (Rukhyati, 2018). Guru PAI merupakan ujung tombak dan komponen yang turut menentukan keberhasilan penyelenggaraan pendidikan di sekolah setempat.

Keberhasilan penyelenggaraan Pendidikan Agama Islam ditentukan pula oleh motivasi kerja guru PAI. Para guru PAI akan dapat memberikan layanan pendidikan berupa kegiatan belajar mengajar dengan baik, semangat yang tinggi dan penuh gairah akan berimplikasi dengan kedisiplinan guru PAI dalam bekerja. Semakin tinggi tingkat disiplin guru PAI, akan semakin tinggi tingkat motivasi dan kepuasan kerja. Demikian sebaliknya, rendahnya tingkat kedisiplinan guru PAI, akan semakin rendah pula tingkat keberhasilan motivasi dan kepuasan kerja guru PAI di sekolah.

Berdasarkan penelitian pendahuluan diperoleh gambaran bahwa guru Pendidikan Agama Islam memiliki motivasi kerja, namun seringkali mereka mengeluh atas pekerjaan dalam mendidik, mengajar dan melatih siswa, sehingga terkadang mengurangi tingkat kedisplinan mereka dalam melaksanakan tugasnya sehari-hari.

Dengan demikian masalahnya adalah apakah terdapat hubungan antara motivasi dan kepuasan kerja dengan kedisiplinan guru PAI yang bertugas di Sekolah Dasar Negeri Pendidikan Se-kecamatan Banjaran kabupaten Majalengka. 


\section{Metode Penelitian}

Penelitian ini menggunakan metode survei dengan teknik asosiatif. Artinya mencari pengaruh antar variabel yang diteliti dengan pendekatan kuantitatif. Sedangkan alat pengumpulan data ini dapat diperoleh data yang cukup banyak, dengan dana dan waktu yang relatif terbatas. Sedangkan untuk melihat hubungan antara motivasi dan kepuasan kerja dengan kedisiplinan guru PAI di Sekolah Dasar Negeri Se-Kecamatan Kabupaten Majalengka dengan menggunakan path analisis. Populasi dalam penelitian ini adalah guru PAI di Sekolah Dasar Negeri Se-Kecamatan Banjaran Kabupaten Majalengka yang berjumlah sebanyak 36 orang. Dalam pengumpulan data, penulis menggunakan teknik Metode Interview, Metode Angket, Metode Observasi, dan dokumentasi.

\section{Hasil dan Pembahasan}

Instrumen kedisiplinan guru adalah guru yang taat dan patuh dengan peraturanperaturan, ketentuan-ketentuan yang berlaku di dalam organisasi baik yang tertulis maupun yang tidak tertulis, yang didasari oleh kesadaran, keinsafan, dan rasa tanggung jawab dengan tugas dan wewenang yang diberikan kepadanya, serta memiliki kesanggupan untuk melaksanakan dan mengutamakan kepentingan pekerjaan organisasi daripada kepentingan pribadinya. indikator-indikator yang dapat dijadikan sebagai dasar penilaian kedisiplinan guru, ialah: (1) kepatuhan dan ketaatan dengan peraturan, (2) kepatuhan dengan ketentuan jam kerja, (3) kepatuhan dalam melakukan perintah dinas, (4) tanggung jawab dengan tugas, (5) kesadaran dalam melaksanakan tugas

Tabel 1

Saya mentaati Kode Etik Guru

\begin{tabular}{llrc}
\hline No & \multicolumn{1}{c}{ Alternatif Jawaban } & f & $\%$ \\
\hline \multirow{2}{*}{1 a. Selalu } & 24 & 64.86 \\
& b. Sering & 13 & 35.14 \\
c. Kadang-kadang & 0 & 0.00 \\
& d. Selalu & 0 & 0.00 \\
& e. Tidak selalu & 0 & 0.00 \\
\multicolumn{1}{c}{ Jumlah } & 37 & 100.00 \\
\hline
\end{tabular}

Dari tabel di atas diperoleh gambaran dan hasilnya adalah sebanyak 24 responden $(64.86 \%)$ menyatakan selalu, 13 responden $(35.14 \%)$ menyatakan sering, 0 responden $(0.00 \%)$ menyatakan kadang-kadang, 0 responden $(0.00 \%)$ menyatakan selalu dan 0 responden $(0.00 \%)$ menyatakan tidak selalu.

Tabel 2

\begin{tabular}{rrrc}
\multicolumn{4}{c}{ Saya melaksanakan tugas sesuai peraturan yang ditetapkan } \\
\hline No & \multicolumn{1}{c}{ Alternatif Jawaban } & \multicolumn{1}{c}{ f } & $\%$ \\
\hline \multirow{2}{*}{2 a. Selalu } & 20 & 54.05 \\
b. Sering & 17 & 45.95 \\
c. Kadang-kadang & 0 & 0.00 \\
d. Selalu & 0 & 0.00 \\
e. Tidak selalu & 0 & 0.00 \\
\multicolumn{1}{r}{ Jumlah } & 37 & 100.00 \\
\hline
\end{tabular}


Dari tabel di atas diperoleh gambaran dan hasilnya adalah sebanyak 20 responden $(54.05 \%)$ menyatakan selalu, 17 responden $(45.95 \%)$ menyatakan sering, 0 responden $(0.00 \%)$ menyatakan kadang-kadang, 0 responden $(0.00 \%)$ menyatakan selalu dan 0 responden $(0.00 \%)$ menyatakan tidak selalu.

Tabel 3

Sebelum mengajar saya menyusun program pembelajaran

\begin{tabular}{llrc}
\hline No & \multicolumn{1}{c}{ Alternatif Jawaban } & f & $\%$ \\
\hline \multirow{2}{*}{3} & a. Selalu & 15 & 40.54 \\
& b. Sering & 21 & 56.76 \\
c. Kadang-kadang & 1 & 2.70 \\
& d. Selalu & 0 & 0.00 \\
& e. Tidak selalu & 0 & 0.00 \\
\multicolumn{1}{c}{ Jumlah } & 37 & 100.00 \\
\hline
\end{tabular}

Dari tabel di atas diperoleh gambaran dan hasilnya adalah sebanyak 15 responden $(40.54 \%)$ menyatakan selalu, 21 responden $(56.76 \%)$ menyatakan sering, 1 responden $(2.70 \%)$ menyatakan kadang-kadang, 0 responden $(0.00 \%)$ menyatakan selalu dan 0 responden $(0.00 \%)$ menyatakan tidak selalu.

Tabel 4

Saya menyusun program pembelajaran sesuai dengan standar isi dan kalender pendidikan

\begin{tabular}{llrc}
\hline No & \multicolumn{1}{c}{ Alternatif Jawaban } & f & $\%$ \\
\hline \multirow{2}{*}{4} & a. Selalu & 4 & 10.81 \\
& b. Sering & 5 & 13.51 \\
c. Kadang-kadang & 9 & 24.32 \\
& d. Selalu & 13 & 35.14 \\
& e. Tidak selalu & 6 & 16.22 \\
\multicolumn{1}{c}{ Jumlah } & 37 & 100.00 \\
\hline
\end{tabular}

Dari tabel di atas diperoleh gambaran dan hasilnya adalah sebanyak 4 responden (10.81\%) menyatakan selalu, 5 responden (13.51\%) menyatakan sering, 9 responden $(24.32 \%)$ menyatakan kadang-kadang, 13 responden $(35.14 \%)$ menyatakan selalu dan 6 responden $(16.22 \%)$ menyatakan tidak selalu.

Tabel 5

\begin{tabular}{|c|c|c|c|}
\hline \multicolumn{4}{|c|}{ Saya berusaha tepat waktu datang ke lokasi pekerjaan } \\
\hline No & Alternatif Jawaban & $\mathrm{f}$ & $\%$ \\
\hline \multirow{6}{*}{5} & a. Selalu & 3 & 8.11 \\
\hline & b. Sering & 8 & 21.62 \\
\hline & c. Kadang-kadang & 7 & 18.92 \\
\hline & d. Selalu & 16 & 43.24 \\
\hline & e. Tidak selalu & 3 & 8.11 \\
\hline & Jumlah & 37 & 100.00 \\
\hline
\end{tabular}

Dari tabel di atas diperoleh gambaran dan hasilnya adalah sebanyak 3 responden $(8,11 \%)$ menyatakan selalu, 8 responden $(21,62 \%)$ menyatakan sering, 7 responden $(18,92 \%)$ 
menyatakan kadang-kadang, 16 responden (43,24\%) menyatakan selalu dan 3 responden $(8,11 \%)$ menyatakan tidak selalu.

Adapaun berdasar perhitungan uji korelasi sederhana (r) didapat korelasi antara motivasi kerja terhadap Kedisiplinan guru ( $\mathrm{r}$ ) adalah 0,749 dan dibandingkan $\mathrm{r}$ tabel dengan tabel terlihat angka untuk $\mathrm{n}=37$ adalah 0,325. dengan demikian mencapai angka taraf signifikan 5\% atau mencapai tingkat kenyakinan 95\%. Sedangkan dengan perhitungan regresi diperoleh angka 0,749 atau $74,9 \%$ dan sisanya $25,1 \%$ dipengaruhi oleh faktor lain artinya tingkat hubungan dalam kategori kuat.

Berdasarkan uji korelasi sederhana ( $\mathrm{r}$ ) didapat korelasi antara kepuasan kerja terhadap kedisiplinan guru (r) adalah 0,724 dan dibandingkan $\mathrm{r}_{\text {tabel }}$ dengan tabel terlihat angka untuk $\mathrm{n}=$ 37 adalah 0,325, dengan demikian mencapai angka taraf signifikan 5\% atau mencapai tingkat kenyakinan 95\%. Sedangkan dengan perhitungan regresi diperoleh angka 0,724 atau 72,4\% dan sisanya 27,6\% dipengaruhi oleh faktor lain artinya tingkat hubungan dalam kategori kuat.

Berdasarkan uji regresi ganda didapat korelasi antara motivasi kerja dan kepuasan kerja secara bersama-sama terhadap kedisiplinan guru adalah 0,780 atau $78 \%$ dan sisanya $22 \%$ dipengaruhi oleh faktor lain artinya tingkat kontribusi dalam kategori kuat dan dibandingkan $\mathrm{r}_{\text {tabel }}$ dengan tabel terlihat angka untuk $\mathrm{n}=37$ adalah 0,325.

\section{Kesimpulan}

Terdapat hubungan yang signifikan antara motivasi kerja dan kepuasan kerja secara bersama-sama terhadap kedisiplinan guru Pemdidikan Agama Islam Sekolah Dasar tingkat kontribusi dalam kategori kuat.

\section{Daftar Pustaka}

Hasibuan, Malayu SP. (2001). Manajemen Sumber Daya Dasar dan Kunci Keberbasilan (Edisi Revisi). Cetakan Ketiga, PT. Bumi Aksara, Jakarta.

Ilahi, DK., Mukzam, MD., \& Prasetya, A. (2017). Pengaruh Kepuasan Kerja Terhadap Disiplin Kerja dan Komitmen Organisasional. Jurnal Administrasi Bisnis (JAB), 44 (1), 31-39.

Irwanto, T, \& Melinda, TF. (2015). Pengaruh Disiplin dan Motivasi dan Kinerja Pegawai Dinas Peternakan dan Kesehatan Hewan Provinsi Bengkulu. Ekombis Review, 3 (2), 215-228.

Kreitner, Robert., dan Kinicki, Angelo. (2005). Perilaku Organisasi, Penerjemah Suandy Erly. Edisi Kelima. Jakarta: Salemba Empat.

Malthis, R.L dan Jackson. (2001). Manajemen Sumber Daya Manusia. Salemba Empat. Jakarta.

Nahdi, D.S. \& Cahyaningsih, U. (2019). Keterampilan Guru SD Dalam Menghadapi Era Revolusi Industri 4.0. Social, Humanities, and Educational Studies (SHEs): Conference Series, 57-63.

Nawawi, H. (2000). Manajemen strategic dengan ilustrasi organisasi profit dan non profit. Jakarta : Rajawali Perss.

Rivai, Veithzal., dan Sagala, Ella Jauvani (2010). Manajemen Sumber Daya Manusia untuk. Perusahaan: dari Teori ke Praktik. Jakarta: Raja Grafindo Persada.

Robbins, P, Stephen. (2006). Perilaku Organisasi. Edisi X. PT. Indeks. Jakarta. 
Robbins, Stephen P., dan Judge, Timoty A. (2008). Perilaku Organisasi (Organizational Behavior), Terjemahan: Diana Angelica, Ria Cahyani dan Abdul Rosyid, Buku 2, Edisi 12. Jakarta: Salemba Empat.

Rukhyati. (2018). Pengaruh Motivasi Dan Disiplin Kerja Terhadap Kinerja Karyawan di Puskesmas Talise. Jurnal Sinar Manajemen. 5, (2). 98-103.

Sedarmayanti. (2008). Manajemen Sumber Daya Manusia. Cetakan Pertama. PT. Refika Aditama; Bandung. 